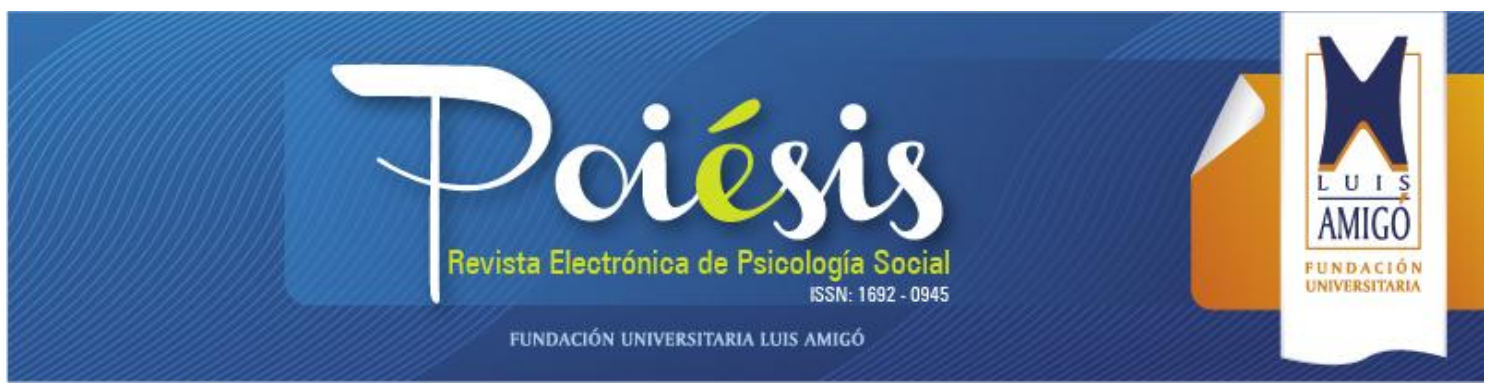

\title{
ACERCA DEL VALOR INSCRIPTUAL DE LAS MARCACIONES CORPORALES ADOLESCENTES
}

\author{
Lorena Bower \\ Licenciada en Psicología \\ Universidad Nacional de San Luis (Argentina) \\ E-mail: lorenabower@gmail.com
}

\begin{abstract}
:
Las marcaciones corporales pueblan la piel del adolescente hipermodermo, al extremo de convertirla en un lienzo en el cual se expresan de modo privilegiado, y bajo las más diversas grafías, noveles modos de vincularse con el cuerpo y con los otros. Se entiende que la eficacia de estas marcas no acaba allí sino que conllevan un valor simbolizante que las hace centrales en la dramática identificatoria adolescente.
\end{abstract}

Observar un tatuaje o un piercing adornando la piel del adolescente se ha convertido, en la actualidad, en un hecho cotidiano. Flores, hadas, calaveras, aros y piedras hacen de esta piel un lienzo sobre el cual exponer un nuevo modo de relacionarse con el cuerpo, un modo posmoderno de vincularse con el corpus.

El corpus, materia de la cual está hecho el hombre, cuerpo que en el curso de la historia se vio acompañado de diversos adjetivos: se decía lo "físico"; lo "somático" o lo "orgánico”. El cuerpo era concebido como: principio de generación material (física); cómo dato -principio (somático) y por último, como disposición articulada de órgano (organismo) ; esto deja claro que se trataba de una noción que reunía en su seno: physys (naturaleza); soma (cuerpo) y organikos (órgano/instrumento). Se avanza desde las culturas premodernas donde el cuerpo no podía disociarse de la comunidad, la naturaleza y el cosmos hacia una modernidad en la cual el paradigma médico- 
biologista da forma a un cuerpo-maquina, con funcionamiento mecánico, autónomo y factible de ser intervenido y reformado; decir "lo orgánico" remite a ese cuerpo entendido como dispositivo instrumentado. Con esos desarrollos el cuerpo real será aquel que responde a lo orgánico, que se agota en el organismo; deslizandose las nociones de "físico" y "somático" a la metafísica primero y luego a la psicología. En este punto se halla la consideración que ha dado sustento a la medicalización y biologización de las prácticas y los discursos sobre el cuerpo, aquella que afirma: la organicidad es lo que constituye la corporeidad.

Puede suceder, no obstante, que debajo de ese cuerpo surja algo, un resto, un dolor intempestivo sin causa aparente, un goce inabordable, que permite sospechar que ese cuerpo del sujeto también late una vida que parece desafiar en parte a la "vida orgánica", o darle su verdadera significación.

De lo que se trata entonces es de fijar como punto de partida que el cuerpo no es la mera resultante de un interjuego de órganos. La introducción de lo inconsciente por la pluma freudiana va a impugnar esa idea organicista para abrir perspectivas clínicas decisivas que responden a la "doble vida" del cuerpo. Algo excede la biología y es sobre ese otro cuerpo que se procura establecer alguna marca con el tatuaje o las cicatrices aún cuando el sustrato sea la dermis.

La práctica de marcar los cuerpos es tan añeja como la cultura misma. Estas marcas han hablado de las relaciones de los sujetos con los dioses; ha servido para vincularse y diferenciarse de otros; eran prácticas esencialmente simbólicas que daban cuenta de inscripciones en el sujeto. Conforme pasó el tiempo este estatuto social comenzó a desvanecerse y el tatuaje pasó a ser un estandarte de individuación e incluso de reivindicación de algunos grupos sociales.

En el siglo XXI la marcación del cuerpo se ha extendido entre los adolescentes pero con carencia de estas significaciones antiguas; el tatuaje parece haberse reducido a un adorno, parte del culto al cuerpo que profesa una sociedad que sobrevalora la apariencia, la imagen y el consumo. Es la era del "voyeurismo generalizado" donde todo se ofrece a la mirada del Otro, al 
respecto vale citar a Wajcman (2011) quien magníficamente caracteriza la época refiriendo: "la mirada de Dios, como otro trascendente, ha descendido al mundo encarnada en dioses tecnológicos que pretenden expandir el dominio de la mirada hacia los confines; como si verlo todo fuera posible".

En esta civilización de la mirada "algo ha empezado a cambiar en la economía de las pulsiones y en la gestión de los cuerpos que le solidaria" (Soler, 2001).

La pulsión es eco en el cuerpo de un decir (del Otro); la organicidad es trascendida y se instala, merced a estas subversiones libidinales, un "segundo cuerpo" pulsional y pulsionalizado que demanda a la vida. El cuerpo es la pantalla de la pulsión escópica; la marca sobre el cuerpo adviene como pintura que, realizada sobre el cuerpo-pantalla, se ofrece a la mirada del Otro.

La adolescencia es un periodo en el cual el cuerpo se modifica sin que el sujeto pueda hacer nada por impedirlo; aparece un real que embiste toda certeza, todo saber construido sobre si. La metamorfosis de la pubertad sumada al empuje pulsional estatuyen un cuerpo con nuevas formas y potencialidades que condiciona el psiquismo adolescente. El sujeto se ve compelido a dar respuesta al problema de la satisfacción de la pulsión, de la construcción de un objeto sexual nuevo y es en ese momento cuando se hace evidente la alteridad, del Otro sexo. Al respecto Imbriano (2003) refiere que durante la adolescencia hay una redistribución de las cartas del deseo y del goce.

El cuerpo adolescente se convierte en un campo de batalla donde se lucha por re-conocerse y re- significarse, por obtener un identidad, algo que le permita apropiarse de esto tan intimo que se ha vuelto extraño y que retorna, siempre, con un dejo siniestro y angustiante. El adolescente se mira al espejo y no se reconoce, igual extrañeza recibe de la mirada de los otros. Paradójicamente este cuerpo (extraño, ajeno) es el único lazo cierto que tiene con el mundo (Le Breton, 2005) de allí que muchas veces la conformación de la imagen propia pase por el decorado del cuerpo, que rápidamente capta la mirada de los otros: para existir hay que ser mirado, hay que ser deseado. 
El cuerpo en primer plano, la apariencia instituida en vía para la socialización con los pares; para captar la mirada del otro y coagular una identidad esquiva.

Por esta vía se llega a considerar que la función psíquica de la marcación corporal tiene que ver con una enunciación, esas marcas en la piel toman el valor de un mensaje, mensaje destinado a captar la mirada del otro y por tanto, ayudar a constituir la identidad. Lacan (1963) refiere: "La incisión tiene precisamente la función de ser para el Otro, de situar en él al sujeto, señalando su puesto en el campo de las relaciones del grupo, entre cada uno y todos los demás".

Las marcas y los distintivos en el cuerpo hacen parte de la identidad, se constituyen en un suministro narcisístico y en un investimento de la representación que le otorga al sujeto una identidad.

En épocas de mudez creciente la imposibilidad de apalabrar convoca a otras escrituras: tatuajes, cortes escrituras que son intentos de lograr alguna inscripción primordial, indeleble y atemporal, resistente a las separaciones y capaces de cimentar el accidentado camino hacia la identidad adulta.

La carencia de emblemas identificatorios claros y guías simbólicas lleva al adolescente a (re) inventar sus propias insignias, ritos reguladores de la economía pulsional que intentan suplir los déficit del Otro. El sujeto adolescente pasa a definirse como "tatuado”, es “el del dragón”, “la serpiente”, "el ángel”; parte de un colectivo que le otorga cierta frágil identidad y le permite decir "soy". La marca otorga un lugar frente a Otro que, caprichosamente, se niega a mirarlo. La marca es entonces grito singular que procura acaparar la atención (del Otro).

Detrás de la fijeza del tatuaje que no deja lugar a la metáfora y circunda al cuerpo en lo más real, se esconde un sin palabras, una grafía aprisionada en un sujeto a la espera de hacerse en el Otro un sitio; alojarse en él y su deseo, coordenadas inexorables para existir y desear. 


\section{Referencias Bibliográficas:}

1. Assoun, P. (1993) "El cuerpo. El Otro metapsicológico", en: Introducción a la metapsicología freudiana. Buenos Aires: Paidós, 1994, pp 231-258.

2. Assoun, P. (1997) Lecciones psicoanalíticas sobre cuerpo y síntoma. Buenos Aires: Nueva visión, 1998.

3. Baudrillard, J. (1980) "El cuerpo o el osario de signos", en: El intercambio simbólico y la muerte.Venezuela : Monte Ávila, $2^{\text {a }}$ ed :1993, pp. 117-142.

4. Dejours, C. (1989) Investigaciones psicoanalíticas sobre el cuerpo - supresión y subversión en psicosomática (traducción de Antonio Marquet), México.

5. Freud, S. (1914e) Introducción del narcisismo, Buenos Aires: Amorrortu, 2005, T. XIV, pp. 7198.

6. Freud, S. (1915b) Pulsiones y destinos de pulsión, Buenos Aires: Amorrortu, 2005, T. XIV, pp. 113-134.

7. Hartman, N., Petronacci, R. (1999) “Tatuaje, escenario de la violencia”, en: Revista de psicoanálisis, Buenos Aires, pp. 905-915.

8. Imbriano, A. (2003) "Un padecimiento generalizado: adolescencia sin salida", en: La odisea del siglo XXI. Efectos de la globalización. Buenos Aires: Letra Viva.

9. Lacan, J. (1936-49) "El estadio del espejo como formador de la función del yo [je] tal como se nos revela en la experiencia psicoanalítica”, en: Escritos I. México: Siglo XXI, 1989, pp. 86-93.

10. Lacan, J. (1962-63) Seminario XI. Los cuatro conceptos fundamentales del Psicoanálisis. Buenos Aires: Paidós, 1990.

11. Le Breton, D. (1990) Antropología del cuerpo y modernidad. Buenos Aires: Nueva Visión.

12. Le Breton, D. (2002) "Les marques corporelles dans les sociétés occidentales: histoire d'un malentendu", en: Signes D'identité. Tatouages, piercings et autres marques corporelles. Paris: Métailié, pp. 23-62.

13. Le Breton, D. (2005) "La escena adolescente: los signos de identidad", en: Adolescence. París: Esprit du Temps, No53, pp. 587-602.

14. Reisfeld, S. (2004) Tatuajes: una mirada psicoanalítica. Buenos Aires: Paidós, 2005.

15. Soler, C. (2001-2002) L'en-corps del sujeto. Barcelona: Publicaciones Digitales, S.A.

16. Wacjman, G. (2011) El ojo absoluto. Buenos Aires: Manantial. 